\title{
Cerebrospinal Fluid Concentrations of Pterins and Metabolites of Serotonin and Dopamine in a Pediatric Reference Population
}

\author{
KEITH HYLAND, ROBERT A. H. SURTEES, SIMON J. R. HEALES, ANN BOWRON, \\ DAVID W. HOWELLS, ${ }^{1}$ AND ISABEL SMITH \\ Institute of Child Health, London WCIN IEH, United Kingdom
}

\begin{abstract}
Accurate diagnosis and management of inborn errors of monoamine neurotransmitter and tetrahydrobiopterin metabolism depend on reliable reference ranges of key metabolites. Cerebrospinal fluid (CSF) was collected in a standardized way from 73 children and young adults with neurologic disease, with strict exclusions. In each specimen, concentrations of homovanillic acid (HVA), 5-hydroxyindoleacetic acid (HIAA), total neopterin, 7,8dihydrobiopterin, and tetrahydrobiopterin ( $\mathrm{BH4}$ ) were measured using HPLC. There was a continuous decrement in CSF HVA, HIAA, and BH4 during the first few years of life; this was independent of height (or length). Agerelated reference ranges for each metabolite are given. Extensive correlations between HVA, HIAA, 7,8-dihydrobiopterin, and $\mathrm{BH} 4$ were further analyzed by multiple regression. Age and CSF BH4 were significant explanatory variables for CSF HIAA, but CSF HIVA had only HIAA as a significant explanatory variable. (Pediatr Res 34: 1014,1993 )
\end{abstract}

\section{Abbreviations}

CSF, cerebrospinal fluid

HVA, homovanillic acid

HIAA, 5-hydroxyindoleacetic acid

NEO, total neopterin

BH2, 7,8-dihydrobiopterin

BH4, tetrahydrobiopterin

BH4 is the cofactor required for the tryptophan, tyrosine, and phenylalanine monooxygenases, the first two being the ratelimiting steps in the biosynthesis of serotonin and dopamine (monoamines) (1). Inborn errors of biopterin metabolism may severely reduce either the biosynthesis or salvage of $\mathrm{BH} 4$, causing hyperphenylalaninemia, a profound deficiency of brain monoamines, and a marked reduction in CSF concentrations of the monoamine metabolites, HVA and HIAA (2). Amine deficiency leads to a characteristic neurologic syndrome (profound hypokinesis, distal chorea, myoclonic epilepsy, hypersalivation, and temperature disturbance) that appears early in life and may be responsive to amine replacement therapy using L-dihydroxyphenylalanine (L-DOPA) and 5-hydroxytryptophan. However, inborn errors of biopterin metabolism are a highly heterogenous

Received October 29, 1992; accepted February 10, 1993.

Correspondence: Keith Hyland, PhD, Baylor Research Institute, Metabolic Disease Center, 3812 Elm St., PO Box 710699, Dallas, TX 75226.

R.A.H.S and A.B. were supported by the Wellcome trust, K.H. and S.J.R.H. by Action Research, and D.W.H. by the Medical Research Council.

' Current address: Dept. of Neurology, Austin Hospital, Heidelberg, Victoria, 3084 Australia. group of conditions and not all are associated with characteristic findings. Indeed, some affected subjects are symptomless. In addition, there are a variety of conditions that may mimic the clinical and/or biochemical picture but that are not due to a primary defect in biopterin metabolism.

In clinical practice, differential diagnosis, decisions on management, and monitoring of therapy for the patients with the inborn errors of $\mathrm{BH} 4$ metabolism are dependent on the correct choice and interpretation of biochemical investigations and require that reliable reference ranges are available for key metabolites. The present article documents such ranges for the following metabolites in CSF: HVA, HIAA, BH4, BH2 (a metabolite of $\mathrm{BH} 4$ ), and $\mathrm{NEO}$ (neopterin plus 7,8-dihydroneopterin, derivatives of the $\mathrm{BH} 4$ precursor dihydroneopterin triphosphate). Although pediatric reference ranges have been established for CSF amine metabolites (3-7) and for total biopterins and neopterins $(8-12)$, these have never been generated using the same CSF samples; therefore, close study of the relationship between these variables has not been possible. These relationships are carefully examined in the present article.

\section{MATERIALS AND METHODS}

CSF samples were obtained from 73 hospitalized patients, aged 2 mo to $19 \mathrm{y}$, with various neurologic diseases in whom no disturbance of the monoamine neurotransmitter or pterin metabolic pathways was suspected and in whom examination of the CSF was indicated for other reasons. Specimens containing visible amounts of blood were excluded. Case records were reviewed at discharge to ensure no evidence of disturbance of these pathways was found after investigation. Patients with movement disorders, inborn errors of amino acid metabolism, basal ganglia calcification, liver disease, infection, immune deficiency, or hemophagocytic syndromes were excluded. The diagnoses at discharge are given in Table 1. Using the statistical methods detailed below, no differences in metabolite concentrations were found between the diagnostic groups.

Lumbar CSF was obtained with the patient in the left lateral position under sedation or light general anesthesia after a 4-h fast. The CSF was frozen at the bedside on dry ice or in liquid

Table 1. Diagnoses at discharge of patients in reference population

\begin{tabular}{lr}
\multicolumn{1}{c}{ Diagnosis } & $n$ \\
\hline Epilepsy & 32 \\
Congenital lactic acidosis & 12 \\
Leukodystrophy & 5 \\
Microcephaly & 4 \\
Cerebral palsy & 4 \\
Asphyxia & 3 \\
Other & 13 \\
\hline
\end{tabular}


nitrogen and stored at $-70^{\circ} \mathrm{C}$ until analysis. The first $0.5 \mathrm{~mL}$ was collected into a plain tube and used for the analysis of HVA and HIAA; the second sample $(1 \mathrm{~mL})$ was collected into a tube containing $1 \mathrm{mg}$ of dithioerythritol and $1 \mathrm{mg}$ of diethylenetriamine pentaacetic acid and used for the pterin analyses. HVA, HIAA, BH4, BH2, and NEO were measured by HPLC as previously described $(13,14)$.

Relationships between variables were examined using Pearson product-motion correlation, multiple regression, and analysis of variance; multiple comparisons were examined using analysis of variance and the Tukey test. Where $\mathrm{BH} 2$ concentrations were below the detection limit $(<0.4 \mathrm{nM})$ these were excluded from the analysis of continuous data but included in the analysis of group data, where their value was assumed to be that at the detection limit. Statistical analyses were performed using Statgraphics (STSC, Inc., Rockville, MD) software.

\section{RESULTS}

Effect of age. CSF concentrations of all the metabolites examined showed a wide variance and appeared to be related to age (Fig. 1). Peak values were found during the first 3 mo of life and then concentrations generally fell to reach a plateau at around $5 \mathrm{y}$ of age. On further examination of the data, however, only HVA $(r=-0.513, p<0.0001)$, HIAA $(r=-0.526, p<$ $0.0001)$, and $\mathrm{BH} 4(r=-0.429, p=0.0002)$ were significantly correlated with age. This was confirmed using analysis of variance with metabolite concentrations grouped according to age
(Table 2). Using regression with the log of the metabolite concentrations as a continuous dependent variable and age as a continuous explanatory variable, best estimates were obtained for the mean and $95 \%$ confidence limit for each metabolite (Fig. 1). Again there was no significant relation between NEO and $\mathrm{BH} 2$ values and age.

Reference ranges for the metabolites at different ages are given in Table 2.

Relationships between metabolites. A highly significant correlation was found between the CSF concentration of HVA and HIAA $(r=0.745, p<0.0001)$ (Fig. 2). Significant correlations were also found between CSF concentrations of $\mathrm{BH} 4$ and those of HVA $(r=0.470, p<0.0001)$ and HIAA $(r=0.647, p<$ $0.0001)$ (Fig. 3). Similarly, BH2 correlated with HVA $(r=0.391$, $p=0.0006)$ and HIAA $(r=0.420, p=0.0002)$, and CSF BH4 was also correlated with $\mathrm{BH} 2(r=0.311, p=0.007)$ (not shown). There was no correlation of NEO with any of the other metabolites.

Multivariate analysis. Because of the interdependence of the metabolite concentrations, we used multiple regression to determine which variables significantly determine metabolite concentration in the CSF. In addition to age and the metabolite concentrations, we also examined the effect of height (or length) in case the effect of age is caused by rostrocaudal gradients of the metabolites along the spinal canal; identical volumes of CSF were obtained from all ages and sizes, and in the smaller patients the CSF would therefore have a more rostral source. The effects of sex and season were also examined. The data was transformed a)

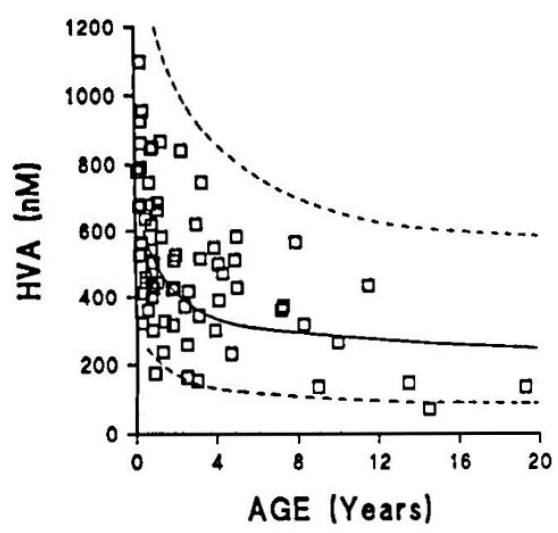

d)

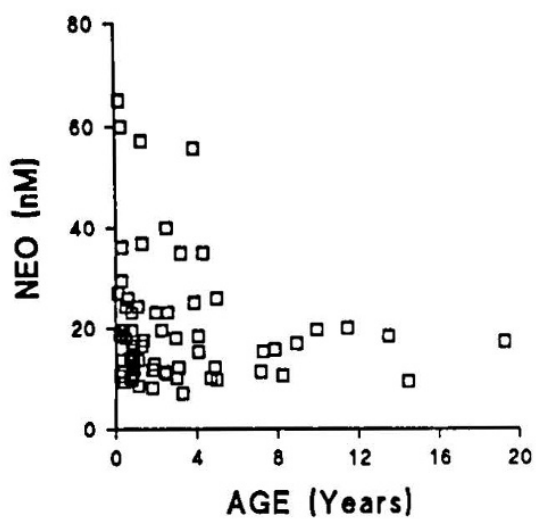

b)

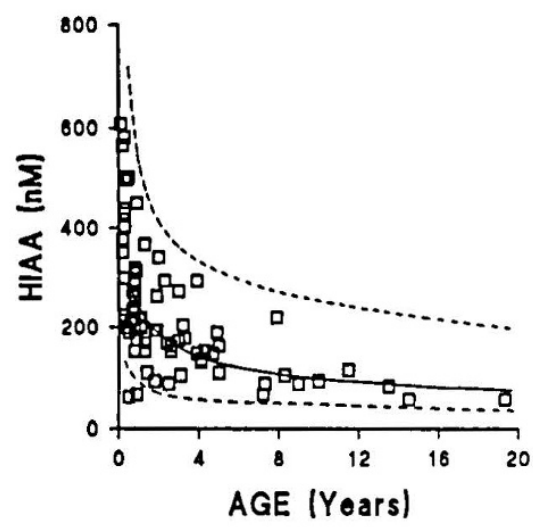

e)

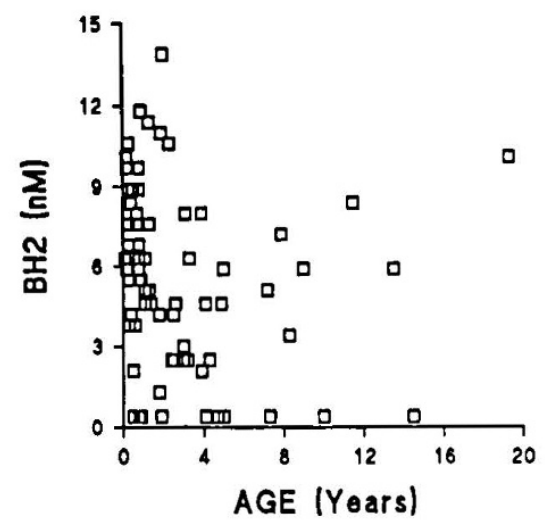

c)

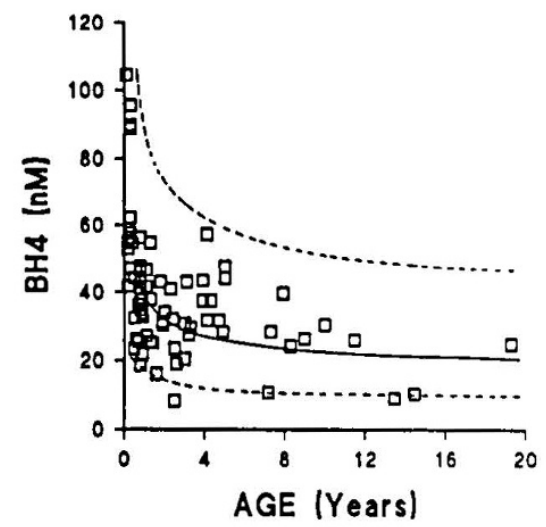

Fig. 1. The relationship between the CSF concentration of the metabolites and age. The regression curve was fitted by the method of least squares after logarithmic transformation; upper and lower curves give the predictive $95 \%$ confidence limits for the logarithmic regression. The effect of age upon CSF metabolite concentration (analysis of variance on the logarithmic regression of metabolite concentration upon age) was significant for: $a$, HVA $\left(\mathrm{F}_{1.71}=34.07, p<0.0001\right) ; b$, HIAA $\left(\mathrm{F}_{1,71}=72.86, p<0.0001\right)$; and $c$, BH4 $\left(\mathrm{F}_{1,71}=39.33, p<0.0001\right)$. There was no significant effect of age upon CSF metabolite concentration for $\mathrm{BH} 2(d)\left(\mathrm{F}_{1,71}=0.360, p=0.78\right)$ or $\mathrm{NEO}(e)\left(\mathrm{F}_{1,71}=1.07, p=0.30\right)$. 
Table 2. Reference ranges for lumbar CSF concentration of $H V A, H I A A, B H 4, B H 2$, and NEO*

\begin{tabular}{ccccccr}
\hline Metabolite & Age (y) & Mean & SD & Minimum & Maximum & $n$ \\
\hline HVA & $0-0.33$ & $714^{\mathrm{a}}$ & 205 & 324 & 1098 & 12 \\
& $0.34-0.66$ & $587^{\mathrm{a}}$ & 203 & 362 & 955 & 8 \\
& $0.67-1.0$ & $508^{\mathrm{a}}$ & 196 & 176 & 851 & 12 \\
& $1.1-5.0$ & $465^{\mathrm{b}}$ & 181 & 154 & 867 & 31 \\
& $5.1-20$ & $281^{\mathrm{b}}$ & 158 & 71 & 565 & 10 \\
HIAA & $0-0.33$ & $417^{\mathrm{a}}$ & 132 & 215 & 608 & 12 \\
& $0.34-0.66$ & $271^{\mathrm{b}}$ & 154 & 63 & 503 & 8 \\
& $0.67-1.0$ & $250^{\mathrm{b}}$ & 98 & 68 & 451 & 12 \\
& $1.1-5.0$ & $185^{\mathrm{b}}$ & 71 & 89 & 367 & 31 \\
BH4 & $5.1-20$ & $98^{\mathrm{c}}$ & 47 & 58 & 220 & 10 \\
& $0-0.33$ & $67^{\mathrm{a}}$ & 21 & 27 & 105 & 12 \\
& $0.34-0.66$ & $37^{\mathrm{b}}$ & 13 & 23 & 55 & 8 \\
& $0.67-1.0$ & $38^{\mathrm{b}}$ & 11 & 19 & 56 & 12 \\
& $1.1-5.0$ & $33^{\mathrm{b}}$ & 11 & 8 & 57 & 31 \\
BH2 & $5.1-20$ & $23^{\mathrm{c}}$ & 10 & 9 & 40 & 10 \\
NEO & All & 5.6 & 3.4 & $<0.4$ & 13.9 & 73 \\
\hline
\end{tabular}

* All values are in nmol. Analysis of variance showed a significant effect of age upon CSF HVA $\left(F_{3.69}=8.35, p<0.0001\right)$, HIAA $\left(F_{3.69}=\right.$ 13.21, $p<0.0001)$, and $\mathrm{BH} 4$ concentration $\left(F_{3.69}=13.81, p<0.0001\right)$, but not upon BH2 $\left(F_{3.69}=1.53, p=0.202\right)$ or $\operatorname{NEO}\left(F_{3.69}=1.48, p=\right.$ $0.217)$. Multiple range testing using Tukey's test shows ${ }^{\mathrm{a}}$ is significantly $(p<0.05)$ different from ${ }^{b}$, which is significantly different from ${ }^{c}$.

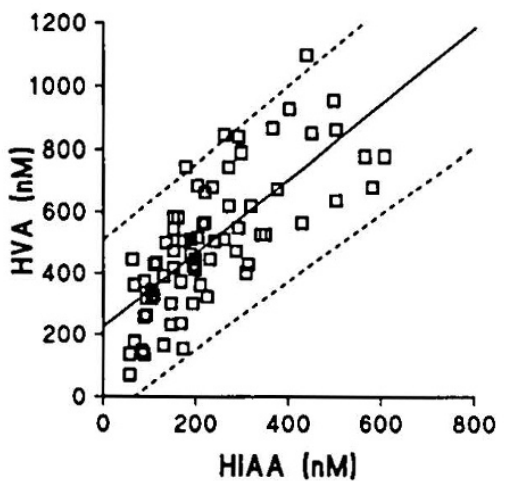

Fig. 2. The relationship between CSF concentration of HVA and HIAA. The regression line was fitted by the method of least squares (analysis of variance on the linear regression: $F_{1,71}=88, p<0.0001$ ); the upper and lower curves are the predictive $95 \%$ confidence limits. Isolated abnormalities of HVA or HIAA may be detected when the values fall outside the confidence limits.

to give optimal normalization for HIAA, neopterin, age and height (logarithmic transformation), and HVA, $\mathrm{BH} 4$, and $\mathrm{BH} 2$ (square root transformation) before the analysis.

After allowing for length, there was still a significant association with age, HVA, and BH4 $(p<0.05)$ for CSF HIAA (Table 3 ); the three variables explained over $70 \%$ of its variance. CSF HVA had only HIAA as a significant explanatory variable, accounting for almost $70 \%$ of the variance. There were significant associations of age and HIAA with CSF BH4, explaining almost $45 \%$ of the variance. CSF BH2 had only $\mathrm{BH} 4$ as a significant explanatory variable, but this accounted for only $10 \%$ of the variance. No significant explanatory variables were found for CSF NEO. There was no significant effect of length or height, sex or season upon any metabolite concentration.

\section{DISCUSSION}

The reference ranges presented here for CSF amine metabolites in children agree closely with those published previously (3-7). The decrement in metabolite concentrations with age over the first few years of life has been observed in all published studies that have examined the effects of age. We have found that the effect of age was independent of the length of the child and therefore unlikely to reflect decreasing concentrations along the spinal canal with increasing size.

We were careful in our sample collection to ensure that the same volume of CSF was collected and that the same portion was used for each analysis. This process removed any variation that could have occurred due to the rostrocaudal gradient that is known to exist for HVA and HIAA (15). In adults, a seasonal variation in HVA and HIAA has been reported (16); in contrast, no variation was found in a pediatric population (17). The CSF samples in our study were collected at random times over several years, and we were able to confirm the lack of seasonal variation after correcting for the effect of age. Unfortunately, detailed timing of CSF collection was not documented; therefore, we were unable to establish whether diurnal variation of metabolite concentrations occurs.

The data demonstrate that age-related reference values for amine metabolites are essential in clinical practice. The $95 \%$ confidence limits based on the logarithm of metabolite values provide the best approach to assessing the likelihood that an individual patient's results are abnormal, but we also give the complete reference range.

Previous studies have also provided pediatric reference values for total biopterins and NEO (8-12), but not for the individual biopterin species $\mathrm{BH} 4$ and $\mathrm{BH} 2$. Although the CSF NEO in the present study is in good agreement with previous work, our values for total biopterins (based on $\mathrm{BH} 4$ plus $\mathrm{BH} 2$ ) are considerably higher. Almost certainly this is due to the special care taken in the present study to avoid oxidative loss of reduced biopterins during sample collection, storage, and analysis. Our previous work has demonstrated that BH4 in CSF is highly unstable and readily breaks down to nonbiopterin compounds unless specimens are collected into appropriate antioxidants and stored at $-70^{\circ} \mathrm{C}$. These studies demonstrated that samples collected in this manner were stable for at least 6 mo at $-70^{\circ} \mathrm{C}$ and up to $2 \mathrm{~h}$ at room temperature (18). For all the metabolites measured here, but particularly for $\mathrm{BH} 4$ and $\mathrm{BH} 2$, it is necessary in clinical practice to pay close attention to standardization of the site, volume, and method of collection of CSF to ensure proper interpretation of the results.

The close relation between CSF dopamine and serotonin metabolites and $\mathrm{BH} 4$ concentrations suggests that the metabolism of these compounds in vivo is normally closely linked. These results are in general agreement with those reported previously in adults $(19,20)$ and with in vitro studies in which alteration of BH4 concentration has been shown to influence monoamine metabolism (21-23). In the multiple regression model, we found that much of the variability in CSF HIAA was explained by age and $\mathrm{BH} 4$, yet a similar proportion of the variability in CSF HVA was explained by HIAA only. Previous studies on the interdependence of these metabolites in CSF have suggested that serotonin turnover may have a regulatory action on dopamine turnover (24), a hypothesis our data support.

In vivo, $\mathrm{BH} 4$ is converted to quinonoid- $\mathrm{BH} 2$ during the hydroxylation of tyrosine and tryptophan. The quinonoid-BH2 is then mostly recycled back to $\mathrm{BH} 4$ by dihydropteridine reductase; however, some of the quinonoid-BH2 escapes this regeneration process and spontaneously rearranges to form 7,8-BH2. It is therefore not surprising that some of the variability of $\mathrm{BH} 2$ was explained by $\mathrm{CSF} \mathrm{BH} 4$. The lack of a relationship between NEO and $\mathrm{BH} 4$, or NEO and dopamine or serotonin metabolites, is consistent with the view that neopterins in CSF and other body fluids have little to do with amine synthesis (except in the specific instance of inborn errors of BH4 synthesis) but arise from macrophages and other immunocompetent cells (25). By far, the most common cause of raised NEO in CSF is stimulation of the macrophage system by virus infection and other immune stimuli (26). Because elevated CSF neopterin is not accompanied by an increase in urine values (27), measurement of CSF NEO is likely 

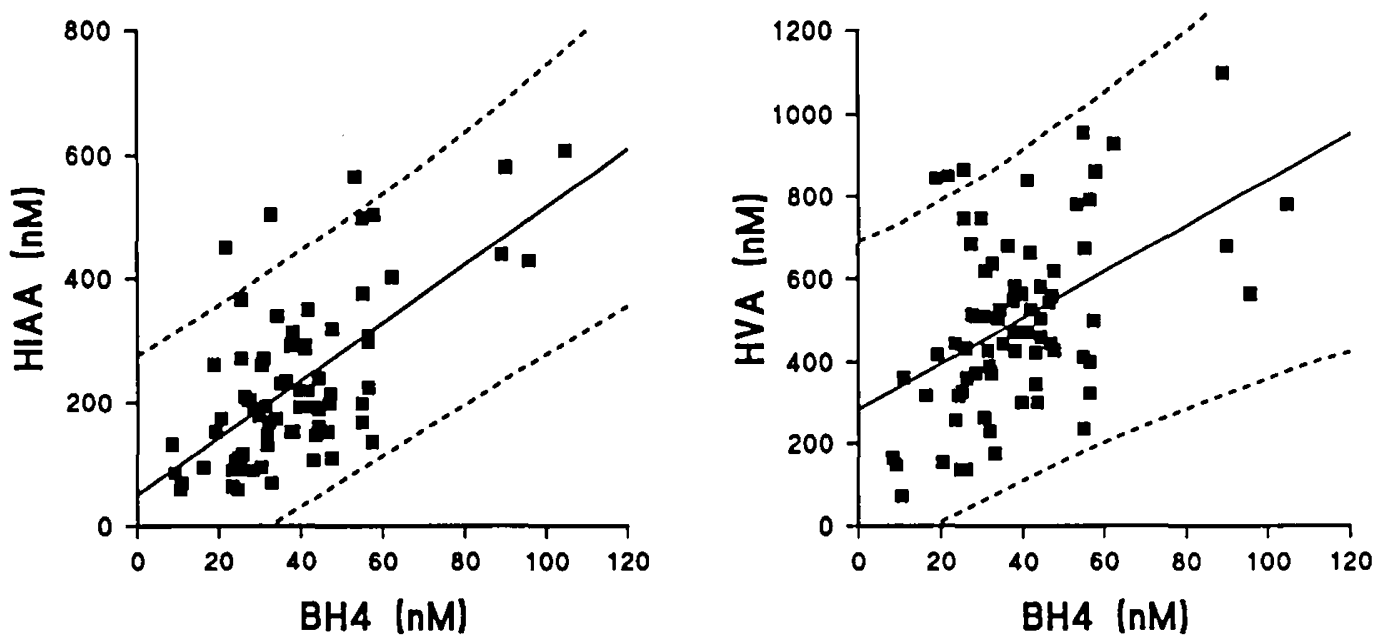

Fig. 3. The relationship between CSF concentrations of BH4 and those of HVA $(a)$ and HIAA $(b)$. The regression lines were fitted by the method of least squares (analysis of variance on the linear regressions: $\mathrm{HVA}_{1,71}=20, p=0.0003$; HIAA $\mathrm{F}_{1.71}=51, p<0.0001$ ); the upper and lower curves are the predictive $95 \%$ confidence limits.

Table 3. Partial correlation table for variables determining CSF HIAA, $H V A$, and BHA found to be significant by multiple regression*

\begin{tabular}{cccc}
\hline & $\log ($ HIAA $) \dagger$ & $\log ($ age $)$ & $\sqrt{(\mathrm{HVA})}$ \\
\hline $\log ($ age $)$ & -0.402 & & \\
& $p<0.001$ & & \\
$\sqrt{(\mathrm{HVA})}$ & 0.609 & -0.031 & \\
& $p<0.001$ & $\mathrm{NS} \ddagger$ & \\
$\sqrt{(\mathrm{BH} 4)}$ & 0.240 & -0.319 & 0.032 \\
& $p<0.05$ & $p<0.01$ & $\mathrm{NS} \ddagger$ \\
\hline
\end{tabular}

* For each cell, above is the partial correlation coefficient, below its significance.

† Optimal normalization of each variable was determined by transforming the variable and using the Kolmogarov-Smirnov test, where the transformation with the lowest and nonsignificant $D$-statistic was chosen.

$\ddagger p>0.05$.

to be clinically useful as an initial test to establish the presence of immune system activation, localized specifically within the CNS.

The reference values presented here have been used not only to confirm and evaluate the need for amine replacement therapy in patients with inborn errors of $\mathrm{BH} 4$ metabolism but also for the differential diagnosis of other disorders in which defective amine metabolism occurs without changes in BH4 (28-31). Wider application of similar CSF analysis in disorders in which there may be disturbance of dopamine or serotonin metabolism $(32,33)$ or in cases in which there is the possibility of CNS immune system activation (27) is likely to be of value in the future.

\section{REFERENCES}

1. Kaufman S 1981 Regulatory properties of pterin dependent hydroxylases: variations on a theme. In: Usdin E, Weiner N, Youdim MBH (eds) Function and Regulation of Monoamine Enzymes. Macmillan, New York, pp 165173

2. Smith I 1990 Disorders of tetrahydrobiopterin metabolism. In: Fernandes J, Saudubray JM, Tada K (eds) Inborn Metabolic Disease. Springer-Verlag, Heidelberg, Germany, pp 183-187

3. Langlais PJ, Walsh FX, Bird ED, Levy HL 1985 Cerebral fluid neurotransmitter metabolites in neurologically normal infants and children. Pediatrics 75:580-586

4. Seifert WE, Fox JF, Butler IJ 1980 Age effect on dopamine and serotonin metabolite levels in cerebrospinal fluid. Ann Neurol 8:38-42

5. Silverstein FS, Donn S, Buchanan K, Johnston MJ 1984 Concentrations of homovanillic acid and 5-hydroxyindole acetic acid in cerebrospinal fluid in human infants in the perinatal period. J Neurochem 43:1769-1772

6. Anderson GM, Hoder EL, Shaywitz BA, Cohen DJ 1985 Neurotransmitter precursors and metabolites in CSF in human neonates. Dev Med Child Neurol 27:207-214
7. Yamamoto $\mathrm{H} 1991$ Changes in CSF neurotransmitters during the first year of life. Pediatr Neurol 7:406-410

8. Sawada Y, Shintaku H, Isshiki G, Hase Y, Tsuruhara T, Oura T 1985 Pteridine values in cerebrospinal fluid in sick children. In: Wachter $\mathrm{H}$, Curtius $\mathrm{H}-\mathrm{Ch}$, Pfleiderer W (eds) Biochemical and Clinical Aspects of Pteridines, Vol 4. Walter de Gruyter, New York, pp 635-642

9. Zoghbi HY, Milstien S, Butler IJ, O'Brian K, Smith E, Kaufman S, Glaze DG, Percy AK 1989 Cerebrospinal fluid biogenic amines and biopterin in Rett syndrome. Ann Neurol 25:56-60

10. Allanson JA, McInnes R, Bradley L, Tarby T, Naylor E, Nardella M 1991 Combined transient and peripheral defects in tetrahydrobiopterin synthesis. J Pediatr 118:261-263

11. Cohen BE, Szeinberg A, Quint J, Normand M, Blonder J, Peled I 1985 Malignant phenylketonuria due to defective synthesis of dihydrobiopterin. Isr J Med Sci 21:520-525

12. Endres W, Ibel H, Kierat L, Blau N, Curtius H-Ch 1987 Tetraydrobiopterin and "non-responsive" dihydropteridine reductase deficiency. Lancet 2:223

13. Hyland K, Smith I, Howells DW, Clayton PT, Leonard JV 1985 The determination of pterins, biogenic amine metabolites and aromatic amino acids in cerebrospinal fluid using isocratic reverse phase liquid chromatography with in series dual cell coulometric electrochemical and fluorescence detection: use in the study of inborn errors of dihydropteridine reductase and 5,10-methylenetetrahydrofolatye reductase. In: Wachter $\mathrm{H}$, Curtius $\mathrm{H}-\mathrm{Ch}$ Pfleidere W (eds) Biochemical and Clinical Aspects of Pteridines, Vol 4. Walter de Gruyter, New York, pp 85-99

14. Howells DW, Smith I, Hyland K 1986 Estimation of tetrahydrobiopterin and other pterins in cerebrospinal fluid using reversed phase HPLC with electrochemical and fluorescence detection. J Chromatogr 381:285-294

15. Kruesi MJP, Swedo SE, Hamburger SD, Potter WZ, Rapoport JL 1988 Concentration gradient of monoamine metabolites in children and adolescents. Biol Psychiatry 24:507-514

16. Brewerton TD, Berrettini WH, Nurnberger JI, Linnoila M 1988 Analysis of seasonal fluctuations of CSF monoamine metabolites and neuropeptides in normal controls: findings with 5-HIAA and HVA. Psychiatry Res 23:257265

17. Swedo SE, Kruesi MJP, Leonard HL 1989 Lack of seasonal variation in pediatric lumbar cerebrospinal fluid neurotransmitter metabolite concentration. Acta Psychiatr Scand 80:644-649

18. Howells DW, Hyland K 1987 Direct analysis of tetrahydrobiopterin in cerebrospinal fluid by high-performance liquid chromatography with redox electrochemistry: prevention of autoxidation during storage and analysis. Clin Chim Acta 167:23-30

19. Lovenberg W, Levine RA, Robinson DS, Ebert M, Williams AC, Calne DB 1979 Hydroxylase cofactor activity in cerebrospinal fluid of normal subjects and patients with Parkinson's disease. Science 204:624-626

20. Kay AD, Milstien S, Kaufman S, Creasey H, Haxby JV, Cutler NR, Rapoport SI. 1986 Cerebrospinal fluid biopterin is decreased in Alzheimer's disease. Arch Neurol 43:996-999

21. Hirata Y, Togari A, Nagatsu T 1983 Studies on tyrosine hydroxylase system in rat brain slices using high performance liquid chromatography with electrochemical detection. J Neurochem 40:1585-1589

22. Brautigam M, Dreesen R, Herken H 1984 Tetrahydrobiopterin and total biopterin content of neuroblastoma (N/E-115,N2A) and pheochromocytoma (PC-12) clones and the dependence of catecholamine synthesis on tetrahydrobiopterin concentration in PC-12 cells. J Neurochem 42:390-396

23. Sawada M, Sugimoto T, Matsuura S, Nagatsu T 1986 (6R)-Tetrahydrobiopterin increases the activity of tryptophan hydroxylase in rat raphe slices. J Neurochem 47:1544-1547

24. Agren H, Mefford IM, Rudorfer MV, Linnoila M, Potter WZ 1986 Interacting 
neurotransmitter systems. A non-experimental approach to the HIAA-HVA correlation in human CSF. J Psychiatr Res 20:175-193

25. Wachter H, Fuchs D, Hausen A, Reibnegger G, Werner ER 1989. Neopterin as marker for activation of cellular immunity: immunologic basis and clinical application. Adv Clin Chem 27:81-141

26. Anonymous 1988 Neopterins in clinical medicine. Lancet 5:509-511

27. Nomoto M, Utatsu Y, Soejima Y, Osame M 1991 Neopterin in cerebrospinal fluid: a useful marker for diagnosis of HTLV-1-associated myelopathy/ tropical spastic paraparesis. Neurology $41: 967$

28. Hyland K, Smith I, Clayton PT, Leonard JV 1985 Impaired neurotransmitter amine metabolism in arginase deficiency. J Neurol Neurosurg Psychiatry 48:1188

29. Clayton PT, Smith I, Harding B, Hyland K, Leonard JV, Leeming RJ 1986 Subacute combined degeneration of the cord, dementia and parkinsonism due to an inborn error of folate metabolism. J Neurol Neurosurg Psychiatry 49:920-927

30. Grant DB, Dunger DB, Smith I, Hyland K 1992 Familial glucocorticoid deficiency with achalasia of the cardia associated with mixed neuropathy, long-tract degeneration and mild dementia. Eur J Pediatr 151:85-89

31. Hyland K, Surtees RAH, Rodeck C, Clayton PT 1992 Aromatic L-amino acid decarboxylase deficiency: clinical features, diagnosis and treatment of a new inborn error of neurotransmitter amine synthesis. Neurology 42:1980-1988

32. Lloyd KG, Hornykiewicz O, Davidson L, Shannak K, Farley I, Goldstein M, Shibuya M, Kelley WN, Fox IH 1981 Biochemical evidence of dysfunction of brain neurotransmitters in the Lesch-Nyhan syndrome. N Engl J Med 305:1106-1111

33. Hyman SL, Porter CA, Page TJ, Iwata BA, Kissel R, Batshaw ML 1987 Behavior management of feeding disturbances in urea cycle and organic acid disorders. J Pediatr 3:558-562 